\title{
The Relationship Between Breastfeeding Practices and Indirect Costs of Health Care: A Case Study of Nurses at Kenyatta National Hospital, Kenya
}

\author{
Oyato Queenter ${ }^{1, *}$, Atieno Ann Ndede-Amadi², Samuel Boaz Otieno ${ }^{3}$ \\ ${ }^{1}$ Ministry of Health, Nairobi Metropolitan Services, Nairobi, Kenya \\ ${ }^{2}$ Indipendent Scholar, Kisumu, Kenya \\ ${ }^{3}$ Indipendent Scholar, Nairobi, Kenya
}

\section{Email address:}

aqueenter74@yahoo.com (O. Queenter), aanamadi15@gmail.com (A. A. Amadi), samwelbotieno@yahoo.com (S. B. Otieno)

*Corresponding author

\section{To cite this article:}

Oyato Queenter, Atieno Ann Ndede-Amadi, Samuel Boaz Otieno. The Relationship Between Breastfeeding Practices and Indirect Costs of Health Care: A Case Study of Nurses at Kenyatta National Hospital, Kenya. Science Journal of Public Health. Vol. 9, No. 1, 2021 , pp. $30-35$. doi: $10.11648 /$ j.sjph.20210901.14

Received: January 14, 2021; Accepted: January 31, 2021; Published: February 9, 2021

\begin{abstract}
Nurses, the primary promoters of Exclusive Breast Feeding (EBF) to mothers, find it challenging to practice it themselves because of their work situations and environments. They care for patients with infections and work in infectious environments. They don't wish to expose their babies to these environments because the babies' immunities are still very low, making them prone to acquiring nosocomial infections, which are costly to treat. Besides, all children, including those of nurses, are prohibited by law from visiting their sick relatives in hospital wards, a factor that preludes the presence of all children from the hospital environment, including those of nurses. The relatively low EBF practice among nurses can be attributed to this fact. Some studies have confirmed that the practice of EBF is low among nurses (e.g. 35.9\% in Ethiopia; $11.1 \%$ in Nigeria; and $21.3 \%$ in Kenya [at Kenyatta National Hospital (KNH)]). The objective of this study was to demonstrate that indirect costs to employers are higher for NON-EBF than for EBF female, lactating, nurses. It has succeeded in demonstrating that lactating nurses who practice EBF during the first six months of their baby's life, take less time off work due to illness of the baby upon returning back to work after maternity leave. There verse is also true in that lactating nurses who practice NON-EBF were found to take more time off to care for their sick babies after they return to work from maternity leave. The focus of the study was to show that overall healthcare costs are lower for all stakeholders under EBF than otherwise. The study used prospective cohort design, mixed methods and purposive sampling technique. The study population was female nurses of reproductive age. Using the employer as the primary beneficiary of a non-absentee workforce, the study was able to demonstrate that employers incur less indirect costs on the section of this cadre of staff that practices EBF than otherwise, $(t=0.71132, d f=4, p$-value $=0.0162)$ and $(r=0.3350988, p<0.05)$. The study was also able to demonstrate further that longer maternity leaves for this cadre of staff may be more beneficial to all stakeholders than otherwise. On these bases, the study was able to suggest change in the Kenyan government maternity leave policy from the current three months to the six months recommended by some sector players like the World Health Organization (WHO) and others, and as supported by other studies in the subject matter.
\end{abstract}

Keywords: Exclusive Breastfeeding (EBF), Respiratory Tract Infection (RTI), Gastro Enteritis (GE), Otitis Media (OM)

\section{Introduction}

EBF is essential for early childhood development [23] because of the extensive evidence for short-term and longterm health benefits, for both mother and infant [21]. EBF supports infants' immune systems and helps protect them from diseases. A study done in 2011 found that babies who are fully exclusively breastfed are less likely to suffer frequent health problems such as Gastro enteritis by $64 \%$, Otitis Media by 23-50\%, Atopic Dermatitis 42\%, Childhood 
Leukaemia 5\%, Childhood Obesity 24\%, Type-1 Diabetes 19\%, and Type-2 Diabetes 39\%, [10]. A similar study also found that babies who are fully exclusively breastfed are less likely to suffer frequent health problems such as respiratory infections, urinary tract infections, eye infections and allergies, compared to the ones who have not been exclusively breastfed [21].

Despite the fact that nurses are trained on the importance of EBF and are the first line promoters of it, several research studies show that they have lower EBF rates than non-nurse working mothers $[12,17,3]$. Other studies have also shown that in order to achieve EBF, lactating working mothers have been encouraged to bring along their babies to work and to take lactation breaks in between work, [5]. Where as this may work for other lactating working mothers, it does not work well for nurses because they work in a highly infectious environment that could predispose their babies to nosocomial infections. Additional studies have also found that nosocomial infections defined as hospital acquired infections, or newly acquired infections that are contracted with in the hospital environment, may be indirectly contributing to low EBF practice among nurses [23], especially in developing countries [22, 13]. A study done in 2009 found that $62.3 \%$ of sampled hospitals had restrictive child visitation policies in place to reduce nosocomial infections among children [7]. In concurrence with this policy, Kenyatta National Hospital (KNH) imposes regulations where by children (including nurses' children) are not allowed to visit their sick relatives in the wards. Nurses constantly provide bed side care to patients and may aid in the spread of nosocomial infections among patients, $[1,6,18]$. This may also mean that there is a higher likelihood for these nosocomial infections to be transmitted through these nurses to their breastfeeding infants and there by increase in health care related costs. Infants may also be exposed at the hospital, as studies have found associations of new borns with nosocomial infections $[11,24,9]$. Studies have also found children to acquire nosocomial infections in the wards beside the diagnosis that they were admitted with $[2,14,15]$. An analytic study done in 2001 found that $\$ 3.6$ billion (Ksh 364.14 billion) would be saved if the prevalence of EBF increased from the current rates of $29 \%$ to the $50 \%$ recommended by the Surgeon General. These savings would result from reducing both direct costs (such as formula costs and physician, clinic, hospital, laboratory and procedural fees) and indirect costs (such as time and wages lost by employers through a parent attending to an ill child) [20].

With reference to direct costs, Infant formula costs the average family in the United States between $\$ 1,200$ and $\$ 1,500$ (Ksh121, 380-151, 725) annually [10]. That study found that if 90 percent of children in the United States were exclusively breastfeed for six months, an estimated $\$ 13$ billion (Ksh1.3 trillion) annually could be saved from reduced direct and indirect medical expenses [10].

\section{Research Questions, Objectives and Hypothesis}

\subsection{Specific Research Question}

The current study tried to answer a specific Research Question: Are nurses' breastfeeding practices associated within direct health care costs at the employer level?

\subsection{The Broad Objective}

The broad objective of the research was: To determine the relationship between nurses' breastfeeding practice with indirect cost implications to their employers.

\subsection{Null Hypothesis}

The following null hypotheses was set up and tested: $\mathrm{H}_{01}$ : There is no relationship between nurses' breastfeeding practice and indirect cost implications to their employer.

\section{Research Methods}

\subsection{Study Area}

The study was conducted at $\mathrm{KNH}$ which is the largest referral hospital in East Africa.

\subsection{Study Population}

The study population were women (nurses) of reproductive age.

\subsection{Study Sample}

Female, child bearing age nurses at the Kenyatta National Hospital at the time of the study (between January and July 2019).

\subsection{Study Design}

This study adopted prospective cohort design to demonstrate the relationship between nurses' breastfeeding practices with indirect cost of heath care. All $\mathrm{KNH}$ female nurses with children aged 6 to 8 months were targeted for the study. A survey was conducted to identify the EBF mothers to form one arm of the study, while NON-EBF mothers formed the other arm of the study. The EBF mothers were matched by NON-EBF mothers by age of the baby, age of the mother, marital status and parity to avoid biasness.

\subsection{Study Method}

The study used both quantitative and qualitative data collection methods but the dominant method was quantitative. The qualitative method used FGD, KII and indepth interviews to explore and explain the relationship between nurses' breastfeeding practice and indirect cost implications to their employer, KNH. This method was used to explain findings, expand understandings, and validate data from quantitative method through in-depth 
interviews and open ended questions.

\subsection{Sampling Method/Technique}

This adopted purposive sampling technique using random sampling method where all EBF mothers with 6 months, 7 months and 8 months old babies were enrolled into the study. A list of mothers was made and, using random tables, those meeting the specified criteria were chosen. The sample size was determined by Fisher.,et al. (2007) $\mathrm{N}=\mathrm{Z} 2 \mathrm{pq} / \mathrm{d} 2 \mathrm{n}=$ desired sample size $\mathrm{z}=$ standard deviation of required confident level given as 1.96 $\mathrm{p}=$ proportion of the target population. The sample size was 384. Since this kind of study is associated with high drop out of participants, as in any cohort, because it is longitudinal, an increment of $20 \%$ of the sample size was provided to cater for the drop out and hence to increase the response rate. As a result, the sample size was adjusted to $\mathrm{n}=384 * 20 \%=76$, hence the targeted sample size was $384+76=460$.

\subsection{Inclusion and Exclusion Criteria}

The study subjects were female nurses (employees of $\mathrm{KNH}$ ) who had six-month to eight-month old infants. These nurses had a history of having practiced breastfeeding before the study begun. To avoid bias, the study systematically included only nurses with infants with no history of underlying diseases that would interfere with immunity like sickle cell disease, HIV, and leukaemia, just to mention a few.

\subsection{Ethical Considerations}

The research approval was given by $\mathrm{KNH} / \mathrm{University}$ of Nairobi (UoN) and GLUK ERC.

\section{Study Results}

The findings of this study were presented as follows:

\subsection{Description of the Study Sample}

The study sample was four hundred thirty five (435) female, breastfeeding nurses at the $\mathrm{KNH}$ at the time of the study. Of interest in the study was distinction between those that breastfed exclusively (EBF) and those that did not (NON-EBF). Of the 435,215 were classified as EBF while 220 were classified as NON-EBF.

\subsection{Breastfeeding Status in Relation to Indirect Cost}

The indirect cost in relation to breastfeeding practices in this study was analysed by time and wages lost by the employer when the lactating nurses were given time off duty because their babies were ill.

\subsubsection{Breastfeeding Status in relation to Time and Wages Lost}

The participants were asked to state the number of days they were given to be off duty by their employer when the baby was ill of RTI, GE and OM. The association between feeding practices with time lost was processed and displayed as shown in the figure below.

\section{Feeding practice with Time lost}

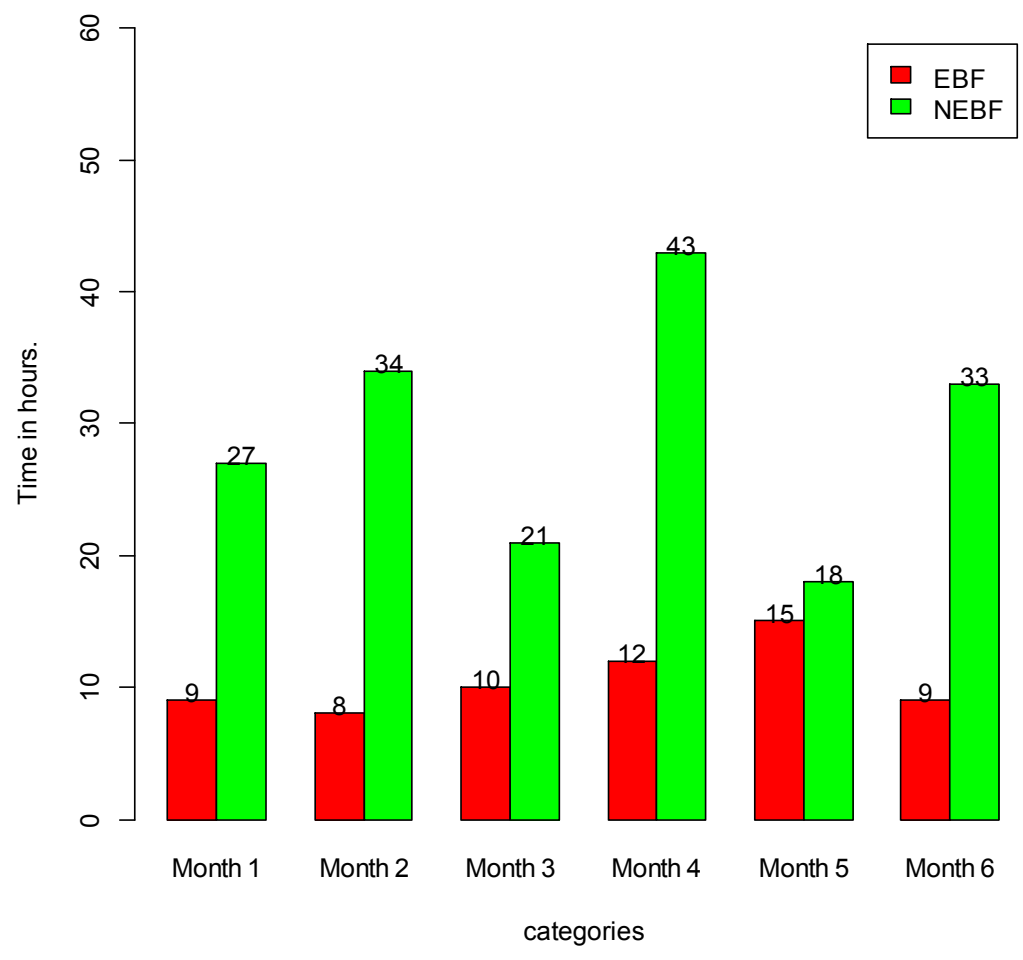

Figure 1. Breastfeeding status in relation to Time and Wages lost. 
Figure 1 indicates that NON-EBF respondents took more days off duty compared to the EBF respondents because their children were sick.

Month four of the follow up recorded the highest number of days lost where NON-EBF respondents were given 43 days while the least loss was at month two where the respondents were given 8 days off duty by their employer. The many days lost in month four by the NON-EBF respondents were probably due to increased RTI and GE.

From their human resource department, these nurses are paid on average Ksh2,500 wages per day.

A total 239 days was issued to the respondents by the employer in the six month follow up which is equivalent to $(239 * 2,500)=\mathrm{K} s h 597,500$ with EBF respondents having 63 days which is $(63 * 2,500)=\mathrm{Ksh} 157,500$ while NON-EBF had 176 days which is $(176 * 2,500)=\mathrm{Ksh} 440,000$.

In general, the employer issued many days to the NON-EBF respondents compared to EBF respondents in the six month follow up, hence a lot of money was lost by the employer to the NON-EBF respondents compared to the EBF respondents.

The association was further analysed using t-test and correlation analysis and the results were $(\mathrm{t}=0.71132, \mathrm{df}=4, \mathrm{p}$ value $=0.0162)$ and $(\mathrm{r}=0.3350988, \mathrm{p}<0.05) \quad$ indicating a positive significant relationship hence the more the children were exposed to NON-EBF them or the days were lost hence more money (wages) was lost by the employer.

\subsubsection{Qualitative Summary of Breastfeeding Status in Relation to Time and Wages Lost}

The above findings on association of feeding practice with time and wages lost concur with FGD where a majority of the participants said that NON-EBF mothers are more likely to be off duty to take care of their sick children than EBF mothers. They said that such nurses are paid for many days not worked for, especially when their children are admitted in the ward, they can be absent for up to even two weeks and they still get paid.

One participant said "...it is stressful to work with breastfeeding mothers especially those who didn't do EBF because their children are always sick making them to be absent from work. This causes a lot of inconveniences on the already pre-planned work schedules. The ward can easily be in crisis making the patients to be in danger...".

Table 1. Summary of Indirect Cost of Health care to the employer.

\begin{tabular}{|c|c|c|}
\hline \multicolumn{3}{|c|}{ Indirect cost of health care to the employer in Ksh } \\
\hline & EBF & NON-EBF \\
\hline Time lost in days & 63 & 176 \\
\hline Wages lost in Ksh & 157,500 & 440,000 \\
\hline Total Indirect cost & 157,500 & 440,000 \\
\hline Total Indirect cost for EBF and NON-EBF & 597,500 & \\
\hline
\end{tabular}

From table 1, a total of Ksh 597,500 was spent as in-direct cost by the employer (KNH) to pay the respondents when they were off duty because their children were ill. $26.4 \%$ (Ksh 157,500) and $73.6 \%$ (Ksh 440,000) was spent by the employer on EBF and NON-EBF respondents respectively.
The association was further analysed using t-test and correlation analysis and the results were $(\mathrm{t}=0.71132, \mathrm{df}=4, \mathrm{p}$ value $=0.0162)$ and $(\mathrm{r}=0.3350988, \mathrm{p}<0.05)$ indicating a positive significant relationship hence the more the children were exposed to NON-EBF the more the days were lost hence more money (wages) was lost by the employer.

\section{Discussion: Breastfeeding Status in Relation to Time and Wages Lost}

The findings of this study: the relationship between breastfeeding practices and indirect cost were compared with the findings of other scholars as discussed below.

The sample of 435 nurses was further divided into two groups of those who practiced Exclusive Breastfeeding (EBF) with 220 respondents and those who did not (NON-EBF) were 215. This study found that NON-EBF respondents were given many days off duty by their employer compared to the EBF respondents when their children suffered from RTI, GE and OM. Month four of the follow up recorded the highest number of days lost where NON-EBF respondents were given 43 days while the least loss was at month two where the respondents were given 8 days off duty by their employer.

A total 239 days was issued to the respondents by the employer in the six month follow up which is equivalent to $(239 * 2,500)=\mathrm{Ksh} 597,500$ with EBF respondents having 63 days which is $(63 * 2,500)=$ Ksh 157,500 while NON-EBF had 176 days which is $(176 * 2,500)=\mathrm{K} \operatorname{sh} 440,000$.

In general, the employer issued many days to the NONEBF respondents compared to EBF respondents in the six month follow up, hence a lot of money was lost by the employer to the NON-EBF respondents compared to the EBF respondents.

The association was further analysed using $\mathrm{t}$-test and correlation analysis and the results were $(\mathrm{t}=0.71132, \mathrm{df}=4, \mathrm{p}$ value $=0.0162)$ and $(\mathrm{r}=0.3350988, \mathrm{p}<0.05)$ indicating a positive significant relationship hence the more the children were exposed to NON-EBF the more the days were lost hence more money (wages) was lost by the employer.

The findings of this study agree with the findings of a study done in 2001 titled: The Economic Impact of Breastfeeding which found that EBF for six months can benefit employers overtime, as mothers are less likely to miss work to take care of an ill child. Fewer missed days of work results in a more stable work force, [19].

Similarly, the findings of this study support the findings of a study done in 1995 titled: Comparison of maternal absenteeism and infant illness rates among Breastfeeding and Formula feeding women in two co-operations which found that approximately $28 \%$ of the infants in the study had no illnesses; $86 \%$ of these were exclusively breastfed and $14 \%$ were formula-fed. $25 \%$ of child illnesses occurred among EBF babies while $75 \%$ were among the formula-fed group. The study concluded that fewer and less severe infant illnesses and less maternal absenteeism were found in the 
EBF group compared to formula-fed group, [16].

The findings of this study also concur with the findings of a study done in 2011 titled: The Economic burden of Infant Formula which showed that the economic burden from infant formula purchase and out-of-pocket medical expenditure exceeded \$400million (Ksh 40.5 billion) in 2003. This cost was aside from other costs, such as absenteeism from work to care for the sick child. The study concluded that these expenses caused an unnecessary burden on Filipino families not practicing EBF to their children and that the money could instead have been invested in education and other social services [8].

The findings of this study also agree with the findings of a study done in 1997 titled: Breastfeeding and Formula feeding: A preliminary Economic Analysis which revealed that a minimum of $\$ 11.5$ million (Ksh 1.2billion) could be saved each year in Australia if the prevalence of EBF at three months was increased from $60 \%$ to $80 \%$. This assessment was based on costs for four illnesses only, as well as educational costs associated with neuro-developmental impairment, and thus is an under estimate of the total cost savings. The study demonstrated that there is evidence that increasing the prevalence of EBF may achieve further cost savings through reduction in these verity and duration of infant illness and through reduction in maternal absenteeism from work, [4].

\section{Conclusion and Recommendation}

Generally, this study found that NON-EBF respondents were given many days off duty by their employer compared to the EBF respondents when their children were ill during the six month follow up, hence a lot of money was lost by the employer to the NON-EBF respondents compared to the EBF respondents.

\subsection{Conclusion}

In conclusion, this study demonstrated that there was a positive significant relationship between breastfeeding practice and time lost indicating that the more the children were exposed to NON-EBF the more the days were lost hence more money (wages) was lost by the employer.

\subsection{Recommendation}

From the study it can be recommended that all lactating working mothers like nurses should be given a six months maternity leave in order to achieve EBF. This will reduce disease incidences and in-direct cost of health care.

\section{Definition of Terms}

1) Infant Morbidity is the state of being symptomatic or unhealthy for a disease or condition in a child below one year of age. It is usually represented or estimated using prevalence or incidence.

2) Prevalence describes the proportion of the population with a given symptom or quality (WHO \& UNICEF,
2015). Infant morbidity in this study referred to a child under one year old having a disease in this case RTI, GE and OM.

3) EBF may provide significant economic benefits in terms of defraying or reducing both direct and indirect costs.

4) The direct costs are related to physician, clinic, hospital, laboratory and procedural fees. Other direct economic benefits to a family may be no or reduced costs to buy infant formula for the first year after birth.

5) Indirect costs in this study related to time and wages lost by parents (primarily mothers/nurses) attending to an ill child. Ideally, attributing costs to time and wages lost by parents attending to a sick child should be considered when estimating the possible economic benefits of breastfeeding to the both the mother and her employer.

\section{References}

[1] Ali, A. (2018). The role of Nursing in Prevention and Control of Hospital Acquired Infections (HAI). Nursing Diagnosis \& Midwifery. J Nurs Health Stud 2018. Volume: 3. Doi: 10.21767/2574-2825-c4-012.

[2] Balaban et al., (2012). Nosocomial infections in the general pediatric wards of a hospital in Turkey. Jpnjinfect Dis. 2012 Jul; 65 (4): 318-21.

[3] Berihun, A., \& Berhanu, B. (2013). Breastfeeding practice and associated factors among female nurses and midwives at North Gondar Zone, North west Ethiopia: a cross-sectional institutional based study. Dachew and Biffu International Breast feeding Journal 2014, 2 9: 11. $\mathrm{http} / / / \mathrm{www}$.internationalbreastfeedingjournal.com/content/9/1/11.

[4] Drane, D. (1997). Breastfeeding and formula feeding: a preliminary economic analysis. Breastfeed Rev. 1997: 5 (10): $7-15$.

[5] Dun Dery, E., \& Laar, A. (2016). Exclusive Breastfeeding among city-dwelling Professional Working Mothers in Ghana. Int Breastfeed J. 2016; 11: 23. doi: 10.1186/s13006-016-00838.

[6] Emily, R., \& Trish, M. (2011). Hospital Epidemiology and Infection Control in Acute-Care Settings. Clinical Microbiology Reviews, Jan. 2011, p. 141-174. Doi: 10.1128/CMR.00027-10.

[7] Hila, J (2009). Child Visitation Policy and Practice for Maternity Units. MCN Am J Matern Child Nurs. Nov-Dec 2009; $\quad 34 \quad$ (6): $\quad 372-7 . \quad$ DOI: 10.1097/01.NMC.0000363686.20315.d5.

[8] Howard, L et al., (2011). The Economic Burden of Infant Formula on Families with Young Children in the Philippines. Journal of human lactation 28 (2) 174-180. DOI: 10.1177/0890334412436719.

[9] Jeong, I et al., (2006). Nosocomial infection in a newborn intensive care unit (NICU), South Korea. BMC Infect Dis. 2006; 6: 103-103.

[10] Karen, S. (2011). The Imperative of Breastfeeding: Policy changes to promote the Health and Economic benefits of infant feeding. American Nursing Association Issue Brief. 
[11] Karla, Detal., (2012). Nosocomial Infections in a Neonatal Intensive Care Unit in South Brazil. Rev. Bras Ter Intensiva. 2012; 24 (4): 381-385.

[12] Oyato, Q. (2020). Factors Associated with Nurses' Breastfeeding Practicesat Kenyatta National Hospital, Kenya. EC Nutrition 15.5 (2020).36-41.

[13] National Nosocomial Infections Surveillance (NNIS) system report, data summary from January 1992 through June 2004, issued October 2004. American Journal of Infection Control, 2004, 32: 470-485.

[14] Raymond, J., \& Aujard, Y. (2000). Nosocomial infections in pediatric patients: a European,multi center prospective study. Infect. Control Hosp. Epidemiol., 21, 260-263.

[15] Richards, M. J., Edwards, J. R., Culver, D. H., etal., (1999). Nosocomial infections in pediatric intensive care units in the United States. National Nosocomial Infections Surveillance System.

[16] Rona, C., Marsha, B., \& Robert, G. (1995). Comparison of maternal absenteeism and infant illness rates among breastfeeding and formula feeding women in two cooperations. Amjpromot. 1995: 10 (2): 148-153.

[17] Sadoh, A. E., Sadoh, W. E., \& Oniyelu, P. (2011). Breast
Feeding Practice among Medical Womenin Nigeria. Niger Med J. 2011 Jan-Mar; 52 (1): 7-12.

[18] Salooje, H., \& Steenhoff, A. (2001). The Health Professional's Role in Preventing Nosocomial Infections. Postgrad Med J 2001; 77: 16-19.

[19] Thomas, M., \& David, M. (2001). "The Economic Impact of Breastfeeding," Pediatric Clinics of North America. Vol. 48, Issue1, February 2001.

[20] Weimer, J. (2001). The economic benefits of breastfeeding: are view and analysis (Report No. 13). Washington DC: U.S. Department of Agriculture, Economic Research Service.

[21] Wilk, E., VanD.,\& Gissler, M. (2011). International Policy overview: Breastfeeding, 1-20.

[22] World Health Organization, (2011). Reporton Burden of Endemic Health Care-Associated Infection Worldwide. A Systemic Review of the literature. http://www.who.int/about/licensing/copyright_form/en/index. html.

[23] World Health Organization \&Unicef. (2015). Breastfeeding Advocacy Initiative For the best startinlife, 9.

[24] Zaid, A et al., (2005). Hospital-acquired neonatal infections in developing countries. Lancet 2005; 365 (9465): 1175-1188. 